\title{
Effects of statin therapy on chronic kidney disease patients with coronary artery disease
}

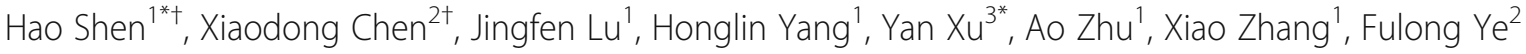 \\ and Yongchun $\mathrm{Gu}^{4}$
}

\begin{abstract}
Background: Long-term persistence of statin therapy provided an ongoing reduction in mortality among patients with and without a known history of CVD, and renoprotective effect on CKD patients. Until now, very few reports are available from China to address the effects of statin therapy in CKD + CAD patients.

Methods: We compared the effects of long-term statin therapy (follow-up time 4 years) in terms of cardiovascular events, all-cause death, and cardiac death among 254 CKD patients with or without CAD.

Results: Long-term statin therapy was much more effective in the CKD + CAD patients compared with CKD patients. In the CAD + CKD patients, long-term statins showed a 22.2\% reduction in the CVs rate $(P=0.012)$. With regard to the all-cause and cardiac deaths, long-term statins had significant treatment effects on the CAD +CKD patients (reduction of about $28.1 \%$ in mortality rates, $P<0.001$ ). In contrast, long-term statin therapy exerted no significant influence on the clinical outcomes of the CKD-only patients.
\end{abstract}

Conclusion: Long-term statin therapy more dramatically reduced the CVs and mortality rates of the CKD patients with concomitant CAD. In contrast, CKD-only patients had a good prognosis and did not appear to require statin treatment.

Keywords: Chronic kidney disease, Statin, Cardiovascular events

\section{Background}

Chronic kidney disease (CKD) is increasing worldwide, it has been recognized as a major and independent risk factor for cardiovascular events (CVs) [1-3], such as coronary artery disease (CAD). Patients with $\mathrm{CAD}$ were frequently shown to have impaired renal function, which may contribute to worse clinical outcomes. On the other hand, most CKD patients die of cardiovascular diseases (CVD) than to progress to end stage kidney disease [4-6].

Statins, the 3-hydroxy 3-methyl-glutaryl coenzyme-A reductase inhibitors,that are well tolerated and the first-

\footnotetext{
*Correspondence: shenhaojyk@126.com; xyfrancecrazy@163.com ${ }^{\dagger}$ Equal contributors

'Department of Clinical Laboratory Medicine, First People's Hospital of Wujiang District, Nantong University, Suzhou, China

${ }^{3}$ Department of Nephrology, First People's Hospital of Wujiang District,

Nantong University, Suzhou, China

Full list of author information is available at the end of the article
}

choice agents for low-density lipoprotein cholesterol (LDL-C) reduction. They are reported to reduce CVs, including myocardial infarction, stroke, and death [7-9]. In patients with mild-to-moderate CKD, statins were found to be effective for primary prevention and to reduce cardiovascular risk [10-14]. Thus, it is believed that statins have both cardiovascular and renal benefits in prevention and treatment.

Long-term persistence of statin therapy provided an ongoing reduction in mortality among patients with and without a known history of CVD, and renoprotective effect on CKD patients $[15,16]$. Until now, very few reports are available from China to address the effects of statin therapy in CKD + CAD patients. Consequently, we compare the effects of long-term statin therapy on CVs and mortality in Chinese CKD patients with or without CAD.

(C) The Author(s). 2018 Open Access This article is distributed under the terms of the Creative Commons Attribution 4.0 International License (http://creativecommons.org/licenses/by/4.0/), which permits unrestricted use, distribution, and 


\section{Methods}

\section{Study participants}

Hospitalization records of 254 patients with CKD (stage3-4) + CAD, or CKD (stage3-4) only were reviewed for demographic data, cardiovascular end points, and long-term regular use of statins. Inpatients were selected from the Wujiang Affiliated Hospital of Nantong University between December, 2010 and December, 2012. Of these, 128 CKD patients were considered to have concomitant CAD if they were diagnosed with CAD by coronary angiogram (CAG), patients received a stent graft or coronary artery bypass grafting surgery according to the extent of their lesions, and 126 CKDonly patients were randomly selected for the control groups. We used a simplified MDRD equation, which is more suitable for Chinese people, to evaluate kidney functions: $186 \times(\text { serum creatinine })^{-1.154} \times \mathrm{Age}^{-0}$. $203 \times(0.742$ for female $)$. The staging of renal function was categorized according to the K/DOQI guidelines $[17,18]$ : stage 3 is a moderate reduction in eGFR $\left(30-59 \mathrm{~mL} / \mathrm{min} / 1.73 \mathrm{~m}^{2}\right)$, stage 4 is a severe reduction in eGFR $\left(15-29 \mathrm{~mL} / \mathrm{min} / 1.73 \mathrm{~m}^{2}\right)$.

Hospitalization records of the 254 patients were reviewed for cardiovascular end points: The primary end points (death, including cardiovascular and noncardiovascular mortality), secondary end points (revascularization, angina, nonfatal myocardial infarction, heart failure, ischemic stroke, and hemorrhagic stroke), Longterm statin users were defined: patients who had taken medication not less than $50 \%$ of the follow-up time minus 30 days to the end of follow-up [19]. Otherwise, the patients were categorized into the no-statin group, and demographic data, included gender, age, body mass index (BMI), history of hypertension and diabetes mellitus [20]. Acute myocardial infarction, angina, and heart failure were diagnosed according to the 2008 European Society of Cardiology guidelines. Stroke was diagnosed by the 2010 Chinese guidelines for diagnosis and treatment of acute ischemic stroke [21].

Exclusion criteria included diagnosis of CAD prior to admission; long-term treatment with lipid-lowering drugs prior to admission; missing blood examination data; patients who died during the hospitalization; patients suffering from major diseases, and expected to survive less than 3 months.

\section{Laboratory measurements}

Various biochemical indexes: fasting blood glucose (FBG), triglyceride (TG), total cholesterol (TC), highdensity lipoprotein cholesterol (HDL-C), LDL-C, lipoprotein (a) (Lp-a), apolipoprotein A-I (ApoA-I), apolipoprotein $\mathrm{B}$ (ApoB), and glycated hemoglobin (HbA1C) were measured via HPLC method [20].

\section{Statistical analyses}

Continuous and categorical data were presented as mean \pm standard deviation (SD) and number (\%), t-test for parametric variables and Wilcoxon tests for nonparametric variables were used to assess group differences (CKD vs CKD + CAD). Comparisons of categorical variables were performed by the Chi-square test. The long-term event-free rate was estimated using KaplanMeier curves, and the log-rank test was used to identify significant differences in survival rates between the two groups. A univariate Cox regression model was used to identify the potential factors that might affect the incidence of cardiovascular events. Furthermore, a multivariate Cox regression analysis was developed to determine those independent predictors. Hazard ratios and corresponding 95\% confidence intervals were sued to describe the intensity for the risk of cardiovascular events. All the statistical analyses were two-tailed. And $P<0.05$ was considered statistically significant. All statistical analyses were performed using SAS 9.1(SAS Institute, Cary, NC, USA).

\section{Results \\ Patients'Characteristics}

A total of 254 patients were examined in this research. The CAD + CKD group included 128 patients. The CKD-only group had 126 patients, respectively. Table 1 summarizes the characteristics of patients in the two groups. The oldest patients and Male gender was found more often in the CKD + CAD group. It is noteworthy that Hypertension, myocardial infarction, smoking, and angina pectoris were more common in the CKD + CAD group. There were significant differences in statin therapy: $90.6 \%$ of CKD + CAD patients took statins compared with only $46.0 \%$ of CKD patients. There was also a significant difference in other medications therapy between the two groups, such as aspirin, $\beta$-blockers, calcium-channel blockers, angiotensin-converting enzyme inhibitors (ACEI) and angiotensin-receptor blockers (ARB). Table 2 shows the laboratory characteristics of the subjects. There was a significant difference in TG, TC, LDL-C, HDL-C, Glucose, HbA1c and DBP at baseline between the two groups, and the other parameters in the baseline characteristics were similar.

\section{Clinical outcomes}

The CKD + CAD group was found to have CVs (54.6\%), all-cause death (24.2\%), and cardiac death (20.3\%) with the higher frequency among the two groups (Fig. 1). The incidence of CVs was lower in the CKD-only group (24. $5 \%)$ compared with that of the CKD + CAD group $(P<$ $0.001)$. Figure 2 shows the cardiovascular events-free survival curves through 4 years for the two groups. The log-rank test revealed that the cardiovascular events 
-free survival rate in the CAD + CKD group was lower compared with that of the CKD group $(\mathrm{P}<0.001)$.

\section{Effects of statins on clinical outcomes}

We compared the effects of statins on the clinical outcomes of the two groups of subjects. The data of Table 3 revealed that long-term statin therapy was much more effective in the CKD + CAD patients compared with CKD patients. In the CAD + CKD patients, long-term statins showed a $22.2 \%$ reduction in the CVs rate $(P=0$. 012). With regard to the all-cause and cardiac deaths, long-term statins had significant treatment effects on the CAD + CKD patients (reduction of about $28.1 \%$ in mortality rates, $\mathrm{P}<0.001)$. In contrast, long-term statin therapy exerted no significant influence on the clinical outcomes of the CKD-only patients.

\section{Predictors for cardiovascular events}

Univariate Cox regression analysis showed that group, age, hypertension, smoking, myocardial infarction, $\beta$ blockers, aspirin, LDL-C, statin discontinuation at final observation might affect the incidence of CVs.

Table 1 The clinical characteristics at baseline

\begin{tabular}{|c|c|c|c|}
\hline Variables & $\begin{array}{l}C K D+C A D \\
(n=128)\end{array}$ & $\begin{array}{l}\text { CKD } \\
(n=126)\end{array}$ & $P^{a}$ \\
\hline \multicolumn{4}{|l|}{ Characteristics } \\
\hline Age (years) & $69.7 \pm 8.4$ & $53.6 \pm 17.8$ & $<0.001$ \\
\hline Male & $90 / 128(70.3)$ & $54 / 126(42.8)$ & $<0.001$ \\
\hline BMI $\left(\mathrm{kg} / \mathrm{m}^{2}\right)$ & $24.3 \pm 2.1$ & $23.4 \pm 2.2$ & 0.001 \\
\hline Hypertension & $95 / 128(74.2)$ & $71 / 126(56.3)$ & 0.003 \\
\hline Diabetes mellitus & $34 / 128(26.5)$ & $36 / 126(28.5)$ & 0.72 \\
\hline Smoking & $58 / 128(45.3)$ & 21/126 (16.6) & $<0.001$ \\
\hline Myocardial infarction & $72 / 128(56.2)$ & $0 / 126(0)$ & $<0.001$ \\
\hline Angina pectoris & $51 / 128$ (39.8) & $0 / 126(0)$ & $<0.001$ \\
\hline Stroke & $7 / 128(5.4)$ & $6 / 126(4.7)$ & 0.798 \\
\hline \multicolumn{4}{|l|}{ Medications } \\
\hline Calcium-channel blocker & $45 / 128(35.1)$ & $64 / 126(50.7)$ & 0.012 \\
\hline ACEI & $57 / 128(44.5)$ & 23/126 (18.2) & $<0.001$ \\
\hline ARB & 46/128 (35.9) & $66 / 126(52.3)$ & 0.008 \\
\hline$\beta$-blocker & $92 / 128(71.8)$ & $37 / 126(28.6)$ & $<0.001$ \\
\hline Loop diuretic & 19/128 (14.8) & $11 / 126(8.7)$ & 0.131 \\
\hline Aspirin & $117 / 128(91.4)$ & $37 / 126(29.3)$ & $<0.001$ \\
\hline Statin & 116/128 (90.6) & $58 / 126(46.0)$ & $<0.001$ \\
\hline \multicolumn{4}{|c|}{$\begin{array}{l}\text { Data are presented as mean } \pm \text { SD or the number and its percentage (\%). } \\
\text { Percentage }=\text { the number of each individual category divided by } \mathrm{n} \\
C A D \text { coronary artery disease, } C K D \text { chronic kidney disease, } A C E I \text { angiotensin- } \\
\text { converting enzyme inhibitor, } A R B \text { angiotensin-receptor blocker, BMI body } \\
\text { mass index } \\
\text { a indicates the comparison of mean or percentage between CKD + CAD group } \\
\text { and CKD group }\end{array}$} \\
\hline
\end{tabular}

Multivariate Cox regression analysis, including the significant predictors above and the marginally significant predictor of myocardial infarction in the univariate model, showed that group, smoking, LDL-C, statin discontinuation were independent predictors of CVs (Table 4). The CKD-only group had the lower risk of CVs (versus CAD + CKD group: HR 0.46, 95\% CI $0.25-$ $0.59, P<0.001$. The findings indicate that the CKD group had the better long-term survival status than CAD + CKD group.

\section{Discussion}

Our study compared the effects of long-term statin treatment in CKD and CAD + CKD patients in China. In the current study, we show that, among the Chinese CKD patients, the rate of CAD was as high as $50.4 \%$ (128/254). In particular, the all-cause and cardiac death rates of the CAD + CKD patients were about twice as high as the CKD-only patients. Thus, just as CKD is a risk factor for CAD, CAD is a risk factor for CKD, emphasizing that CAD and CKD are closely associated diseases with a reciprocal adverse impact. Our data show that long-term statin therapy can significantly improve the clinical outcomes of the CAD + CKD patients, the treatment effect of statins was much more dramatic, with remarkable reductions in the CVs rate (22.2\%), allcause death $(28.1 \%)$, and cardiac death (26.3\%). In contrast, no significant treatment effect of statin was observed in the CKD-only patients. In the current study, the CAD + CKD patients had a high rate of hypertension,

Table 2 The laboratory characteristics at baseline

\begin{tabular}{llll}
\hline Variables & $\begin{array}{l}\text { CKD }+ \text { CAD } \\
(n=128)\end{array}$ & $\begin{array}{l}\text { CKD } \\
(n=126)\end{array}$ & \\
\hline Triglycerides $(\mathrm{mmol} / \mathrm{l})$ & $1.7 \pm 1.1$ & $2.5 \pm 1.3$ & $<0.001$ \\
Total cholesterol $(\mathrm{mmol} / \mathrm{l})$ & $4.8 \pm 1.3$ & $6.6 \pm 2.8$ & $<0.001$ \\
LDL-C (mmol/l) & $6.7 \pm 1.9$ & $4.1 \pm 2.4$ & $<0.001$ \\
HDL-C (mmol/l) & $1.0 \pm 0.4$ & $1.3 \pm 0.4$ & $<0.001$ \\
Glucose (mmol/l) & $7.3 \pm 4.4$ & $9.1 \pm 5.2$ & 0.003 \\
HbA1C $(\%)$ & $6.5 \pm 1.2$ & $7.9 \pm 2.3$ & $<0.001$ \\
SBP (mmHg) & $137.1 \pm 31.2$ & $139.3 \pm 21.9$ & 0.517 \\
DBP (mmHg) & $78.3 \pm 15.1$ & $73.1 \pm 10.2$ & 0.001 \\
ApoA-I (g/l) & $1.3 \pm 2.8$ & $1.3 \pm 0.3$ & 0.999 \\
ApoB (g/l) & $1.0 \pm 2.2$ & $1.0 \pm 0.3$ & 0.999 \\
ApoA-l/B & $1.3 \pm 0.3$ & $1.4 \pm 0.5$ & 0.054 \\
Lp (a) (ng/ml) & $382.3 \pm 326.4$ & $373.4 \pm 394.2$ & 0.845
\end{tabular}

Data are presented as mean \pm SD

$C A D$ coronary artery disease, $C K D$ chronic kidney disease, $\mathrm{HbA1c}$ hemoglobin A1c, ApoA-I apolipoprotein A-I, $A p o B$ apolipoprotein B, HDL-C high-density lipoprotein cholesterol, $L D L-C$ low-density lipoprotein cholesterol, SBP systolic blood pressure, $D B P$ diastolic blood pressure, $L p(a)$ lipoprotein (a)

${ }^{a}$ indicates the comparison of mean between CKD + CAD group and CKD group 


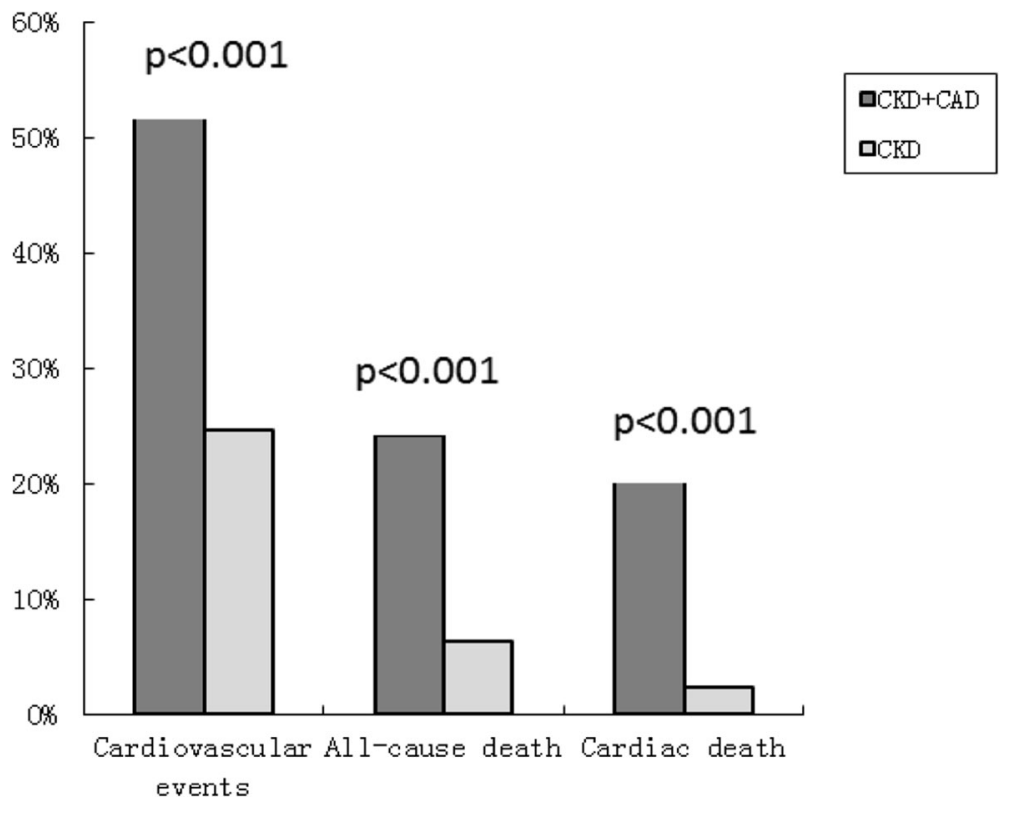

Fig. 1 Clinical outcomes in CKD $+C A D$ and CKD groups

smoking, myocardial infarction, and angina pectoris. The unadjusted determinants of CVs included hypertension, smoking, myocardial infarction, LDL-C level, and the use of $\beta$-blockers and aspirin. After adjustment, smoking, statin therapy, LDL-C level were significant predictors of CVs. These findings are consistent with previous reports in general $[5,6,22]$.
To our knowledge,few studies have compared the effects of long-term statin therapy in the CKD patients with or without CAD from China. Some study [23, 24] compared the effects of statins on the clinical outcomes of CAD patients with or without renal insufficiency; however, there was no CKD-only patient group in their investigation. Longer-term statin therapy may exert

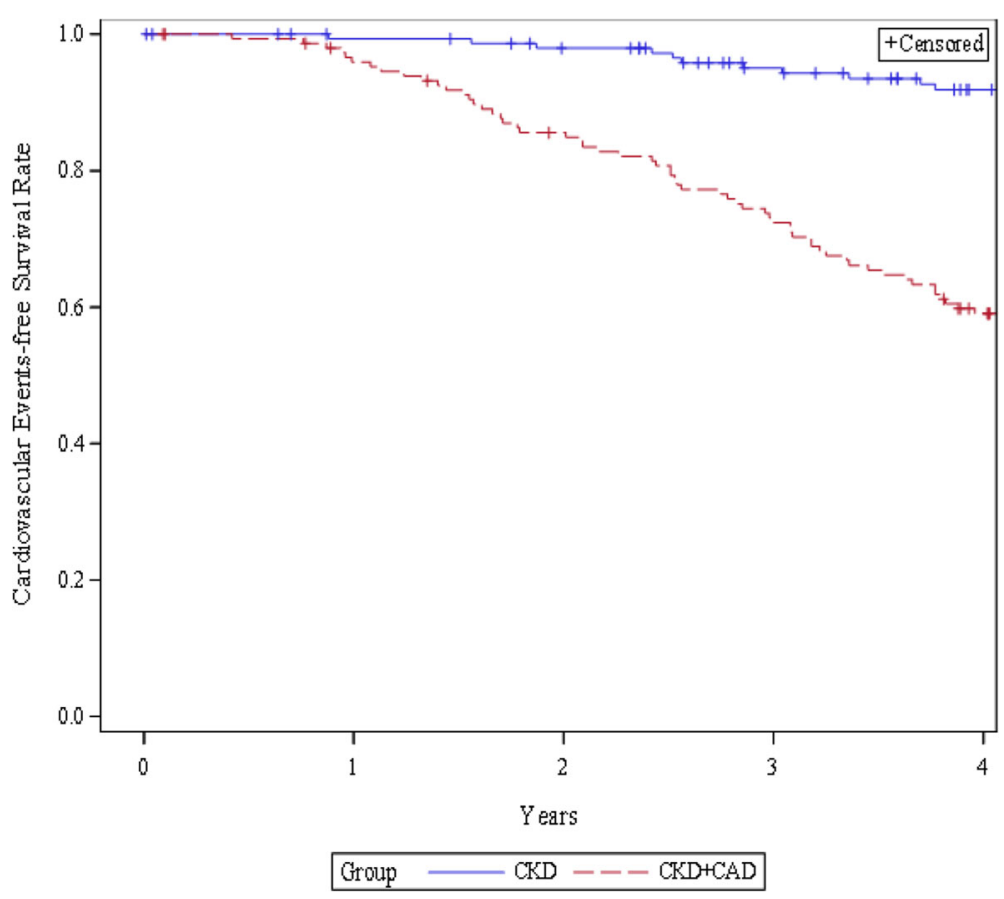

Fig. 2 Kaplan-Meier curves for cardiovascular events free survival rates for the two groups 
Table 3 Effects of statins on clinical outcomes

\begin{tabular}{llll}
\hline Variables & Long-term statins & No statin & $P^{\mathrm{a}}$ \\
\hline CKD +CAD & & & \\
Cardiovascular events & $29 / 66(43.9 \%)$ & $41 / 62(66.1 \%)$ & 0.012 \\
All-cause death & $7 / 66(10.6 \%)$ & $24 / 62(38.7 \%)$ & $<0.001$ \\
Cardiac death & $5 / 66(7.5 \%)$ & $21 / 62(33.8 \%)$ & $<0.001$ \\
CKD & & & \\
Cardiovascular events & $12 / 35(34.2 \%)$ & $19 / 91(20.8 \%)$ & 0.118 \\
All-cause death & $2 / 35(5.7 \%)$ & $6 / 91(6.5 \%)$ & 0.856 \\
Cardiac death & $0 / 35(0 \%)$ & $3 / 91(3.2 \%)$ & 0.56 \\
\hline
\end{tabular}

Data are presented as the number and its percentage (\%) $C A D$ coronary artery disease, $C K D$ chronic kidney disease

${ }^{a}$ indicates the comparison of percentage between Long-term statins group and No statin group more significant treatment effects, and our results show that the extent of reduction in CVs, all-cause deaths, and cardiac deaths appears to be more dramatic compared with the Japanese studies. This suggests that the Chinese CKD + CAD patients are substantially different from those in Japan. Possible reasons for the high morbidity and mortality in China include worse economic conditions, heavier labor, and insufficient medical care. Thus, in CKD + CAD patients with worse clinical outcomes like in China, long-term statin therapy can exert more dramatic treatment effects, and measures should be taken to enhance adherence to statins.

One striking discovery is that the CKD-only patients had very low all-cause or cardiac mortality, and statin therapy did not have a significant impact on the CVs and mortality rates. Statin treatment has been shown to be beneficial for CKD patients not undergoing dialysis $[10,16,25]$; however, previous studies have not separated CKD patients with or without CVD. In the current study, we selectively analyzed the CKD patients who did

Table 4 Predictors for Cardiovascular events according to Cox's proportional hazard analysis

\begin{tabular}{|c|c|c|c|c|c|c|}
\hline \multirow[t]{2}{*}{ Variables } & \multirow[b]{2}{*}{$\mathrm{HR}$} & \multicolumn{2}{|l|}{ Unadjusted } & \multirow[b]{2}{*}{$\mathrm{HR}$} & \multicolumn{2}{|l|}{ Adjusted } \\
\hline & & $95 \% \mathrm{Cl}$ & $P$ & & $95 \% \mathrm{Cl}$ & $P$ \\
\hline$C K D$ versus $C K D+C A D$ & 0.5 & $(0.27-0.68)$ & $<0.001$ & 0.46 & $(0.25-0.59)$ & $<0.001$ \\
\hline Age (years) & 1.32 & $(1.21-1.93)$ & $<0.001$ & 1.1 & $(0.95-1.04)$ & 0.078 \\
\hline Male (versus female) & 0.76 & $(0.57-1.15)$ & 0.545 & & - & \\
\hline Hypertension & 1.61 & $(1.21-2.01)$ & $<0.01$ & 1.16 & $(0.95-1.67)$ & 0.071 \\
\hline Diabetes mellitus & 1.24 & $(0.87-1.72)$ & 0.291 & & - & \\
\hline Smoking & 1.43 & $(1.33-1.81)$ & $<0.01$ & 1.41 & $(1.09-2.11)$ & 0.009 \\
\hline Myocardial infarction & 1.18 & $(1.06-1.89)$ & 0.048 & 1.03 & $(0.91-1.35)$ & 0.121 \\
\hline Angina pectoris & 1.07 & $(0.67-1.46)$ & 0.32 & & - & \\
\hline Stroke & 1.53 & $(0.97-3.16)$ & 0.221 & & - & \\
\hline Calcium-channel blocker & 1.27 & $(0.76-1.50)$ & 0.322 & & - & \\
\hline ACEI & 0.97 & $(0.85-1.30)$ & 0.976 & & - & \\
\hline ARB & 0.89 & $(0.63-1.28)$ & 0.514 & & - & \\
\hline$\beta$-blocker & 1.42 & $(1.12-1.89)$ & $<0.01$ & 1.11 & $(0.72-1.61)$ & 0.55 \\
\hline Loop diuretic & 1.09 & $(0.61-1.76)$ & 0.488 & & - & \\
\hline Aspirin & 1.98 & $(1.56-3.97)$ & $<0.01$ & 1.32 & $(0.68-1.99)$ & 0.601 \\
\hline Triglycerides (mmol/l) & 1.12 & $(0.72-1.81)$ & 0.78 & & - & \\
\hline Total cholesterol (mmol/l) & 1.07 & $(0.87-1.75)$ & 0.64 & & - & \\
\hline LDL-C (mmol/l) & 1.12 & $(1.07-1.62)$ & $<0.001$ & 1.05 & $(1.01-1.25)$ & 0.011 \\
\hline $\mathrm{HDL}-\mathrm{C}(\mathrm{mmol} / \mathrm{l})$ & 0.69 & $(0.46-1.21)$ & 0.222 & & - & \\
\hline Glucose (mmol/l) & 1.23 & $(0.96-1.91)$ & 0.52 & & - & \\
\hline $\mathrm{HbA} 1 \mathrm{c}(\%)$ & 0.96 & $(0.68-1.69)$ & 0.771 & & - & \\
\hline $\mathrm{SBP}(\mathrm{mmHg})$ & 0.97 & $(0.90-1.18)$ & 0.078 & & - & \\
\hline $\mathrm{DBP}(\mathrm{mmHg})$ & 1.08 & $(0.97-1.39)$ & 0.56 & & - & \\
\hline Long-term statins & 0.22 & $(0.19-0.57)$ & $<0.001$ & 0.27 & $(0.21-0.41)$ & $<0.001$ \\
\hline
\end{tabular}

$C A D$ coronary artery disease, $C K D$ chronic kidney disease, $A C E I$ angiotensin-converting enzyme inhibitor, $A R B$ angiotensin-receptor blocker, $S B P$ systolic blood pressure, $D B P$ diastolic blood pressure, HbA1c hemoglobin A1C, HDL-C high-density lipoprotein cholesterol, $L D L-C$ low-density lipoprotein cholesterol 
not have CVD at registration; these patients did not develop significantly increased $\mathrm{CVs}$ and mortality rates during the long follow-up period nor did they show an effective response to statin treatment. Thus, CKD patients free of CVD at baseline appear to have an excellent prognosis and, therefore, may not need statin treatment. This finding may provide a significant guideline regarding statins in CKD patients, and it warrants larger scale studies across multiple clinical centers in China.

There were several limitations in this study. Firstly, this is not a prospective study. Therefore, we need a more carefully controlled prospective study to achieve this purpose in the future. Secondly, the sample size of this study was small. Therefore, future studies that include a larger cohort of patients are necessary to corroborate our findings.

\section{Conclusion}

This study compared CKD patients with or without CAD treated with long-term statins; it provides new insights about the appropriate treatment of these two groups of patients. Long-term statin therapy more dramatically reduced the CVs and mortality rates of the CKD patients with concomitant CAD. In contrast, CKDonly patients had a good prognosis and did not appear to require statin treatment.

\section{Abbreviations \\ Apo: Apolipoprotein; BMI: Body mass index; CAD: Coronary artery disease: CKD: Chronic kidney disease; CVD: Cardiovascular diseases; \\ CVs: Cardiovascular events; DBP: Diastolic blood pressure; eGFR: Estimated glomerular filtration rate; FBG: Fasting blood glucose; HbAlc: Hemoglobin A1c; HDL-C: High-density lipoprotein cholesterol; LDL-C: Low-density lipoprotein cholesterol; SBP: Systolic blood pressure; TC: Total cholesterol; TG: Triglyceride}

\section{Acknowledgements}

This study was supported by the Renal Unit of the First People's Hospital of Wujiang, Suzhou, China.

\section{Funding}

The First People's Hospital of Wujiang (201834)

\section{Availability of data and materials}

Unfortunately, the initial data cannot be shared as it contains confidential information.

\section{Authors' contributions}

SH and CXD planned and supervised the study. LF, YHL, and XY contributed to data collection and enrolled patients. ZA performed the flow mediated dilatation test. ZX wrote the manuscript. YFL and GYC reviewed/edited the manuscript. All authors read and approved the final manuscript.

\section{Ethics approval and consent to participate}

This study was approved by the Committee on Human Research of Wujiang Affiliated Hospital of Nantong University. All patients signed a dedicate informed consent.

\section{Consent for publication}

All patients signed an informed consent to the anonymous use of their clincal data for research purposes at submission for treatment.

\section{Competing interests}

The authors declare that they have no competing interests.

\section{Publisher's Note}

Springer Nature remains neutral with regard to jurisdictional claims in published maps and institutional affiliations.

\section{Author details}

'Department of Clinical Laboratory Medicine, First People's Hospital of Wujiang District, Nantong University, Suzhou, China. ${ }^{2}$ Department of Internal Medicine, First People's Hospital of Wujiang District, Nantong University, Suzhou, China. ${ }^{3}$ Department of Nephrology, First People's Hospital of Wujiang District, Nantong University, Suzhou, China. ${ }^{4}$ Department of Central Laboratory, First People's Hospital of Wujiang District, Nantong University, Suzhou, China.

Received: 9 January 2018 Accepted: 9 April 2018

Published online: 17 April 2018

\section{References}

1. Said A, Desai C, Lerma EV. Chronic kidney disease[J]. Revue Médicale Suisse. 2015;61(9):374.

2. Raghban A, Kirsop J, Tang WHW. Prevention of heart failure in patients with chronic kidney disease[J]. Curr Cardiovasc Risk Rep. 2015;9(1):1-11.

3. Go AS, Chertow GM, Fan D, et al. Chronic kidney disease and the risks of death, cardiovascular events, and hospitalization[J]. NEngl J Med. 2004; 351(13):1296-305.

4. Briasoulis A, Bakris GL. Chronic kidney disease as a coronary artery disease risk equivalent[]]. Curr Cardiol Rep. 2013;15(3):1-6.

5. Tonelli M, Jose P, Curhan G, et al. Proteinuria, impaired kidney function, and adverse outcomes in people with coronary disease: analysis of a previously conducted randomised trial[J]. BMJ. 2006;332(7555):1426.

6. Yagi H, Kawai M, Komukai K, et al. Impact of chronic kidney disease on the severity of initially diagnosed coronary artery disease and the patient prognosis in the Japanese population.[J]. Heart Vessels. 2011;26(4):370-8.

7. Azar RR, Waters DD. Prince's prospects: statins, inflammation, and coronary risk[J]. Am Heart J. 2001;141(6):881-3.

8. Fang CH, Li JJ, Hui RT. Statin, like aspirin, should be given as early as possible in patients with acute coronary syndrome[]]. Med Hypotheses. 2005;64(1):192-6.

9. Tsai NW, Lin TK, Chang WN, et al. Statin pre-treatment is associated with lower platelet activity and favorable outcome in patients with acute noncardio-embolic ischemic stroke[]]. Crit Care. 2011;15(4):R163.

10. Palmer SC, Craig JC, Navaneethan SD, et al. Benefits and harms of statin therapy for persons with chronic kidney disease[J]. Ann Intern Med. 2012; 157(4):263.

11. Ridker PM, Macfadyen J, Cressman M, et al. Efficacy of rosuvastatin among men and women with moderate chronic kidney disease and elevated highsensitivity C-reactive protein: a secondary analysis from the JUPITER (justification for the use of statins in prevention-an intervention trial evaluating R)[J]. J Am Coll Cardiol. 2010;55(12):1266-73.

12. Collins R, Armitage J, Parish S, et al. MRC/BHF heart protection study of cholesterol lowering with simvastatin in 20,536 high-risk individuals[]]. Lancet. 2002;360(9326):7-22.

13. Tonelli M, Isles C, Curhan GC. Effect of pravastatin on cardiovascular events in people with chronic kidney disease[]]. ACC Curr J Rev. 2004;110(12):1557-63.

14. Shepherd J, Kastelein JJ, Bittner V, et al. Effect of intensive lipid lowering with atorvastatin on renal function in patients with coronary heart disease: the treating to new targets (TNT) study[J]. Clin J American Soc Nephrol Cjasn. 2007;2(6):1131

15. Shalev V, Chodick G, Silber H, et al. Continuation of statin treatment and allcause mortality a population-based cohort study.[J]. Arch Intern Med. 2009; 169(3):260-8.

16. Nikolic D, Banach M, Nikfar S, et al. A meta-analysis of the role of statins on renal outcomes in patients with chronic kidney disease. Is the duration of therapy important?[J]. Int J Cardiol. 2013;168(6):5437-47.

17. National Kidney Foundation. KJDOQI clinical practice guidelines for chronic kidney disease: evaluation, classification and stratification. Am J Kidney Dis. 2002;39:51-266 
18. Ma YC, Zuo L, Chen JH, et al. Modified glomerular filtration rate estimating equation for Chinese patients with chronic kidney disease.[J]. J Am Soc Nephrol. 2006;17(10):2937-44.

19. Chodick G, Shalev V, Gerber Y, et al. Long-term persistence with statin treatment in a not-for-profit health maintenance organization: a populationbased retrospective cohort study in Israel[]]. Clin Ther. 2008;30(11):2167-79.

20. Chobanian AV, Bakris GL, Black HR, et al. Seventh report of the joint national committee on prevention, detection, [J]. Microgravity - Science and Technology. 2016;xviii(18):165-9.

21. Liu X, Zhang S, Liu M, et al. Chinese guidelines for endovascular management of ischemic cerebrovascular diseases.[J]. Interv Neurol. 2013; 1(3-4):171-84

22. Seino $\mathrm{Y}$, Nanjo K, Tajima N, et al. Report of the committee on the classification and diagnostic criteria of diabetes mellitus[]]. J Diab Investig. 2010;1(5):212-28.

23. Kaneko H, Yajima J, Oikawa Y, et al. Effects of statin treatment in patients with coronary artery disease and chronic kidney disease[J]. Heart Vessels. 2014;29(1):21-8

24. Natsuaki M, Furukawa $Y$, Morimoto $T$, et al. Renal function and effect of statin therapy on cardiovascular outcomes in patients undergoing coronary revascularization (from the CREDO-Kyoto PCI/CABG registry Cohort-2)[]]. Am J Cardiol. 2012:110(11):1568-77.

25. Lardizabal JA, Deedwania PC. Benefits of statin therapy and compliance in high risk cardiovascular patients[]]. Vasc Health Risk Manag. 2010;6:843-53.

Ready to submit your research? Choose BMC and benefit from:

- fast, convenient online submission

- thorough peer review by experienced researchers in your field

- rapid publication on acceptance

- support for research data, including large and complex data types

- gold Open Access which fosters wider collaboration and increased citations

- maximum visibility for your research: over $100 \mathrm{M}$ website views per year

At BMC, research is always in progress.

Learn more biomedcentral.com/submissions 